\title{
Weight at Time of Procedure
}

National Cancer Institute

\section{Source}

National Cancer Institute. Weight at Time of Procedure. NCI Thesaurus. Code C158523.

The weight of an individual at the time of a procedure. 